\title{
Níveis de glicerina bruta na ensilagem de capim Tifton 85 (Cynodon dactylon): perfil fermentativo e valor nutricional
}

\section{Crude glycerin levels in ensiling grass Tifton 85 (Cynodon dactylon): fermentative profile and nutritional value}

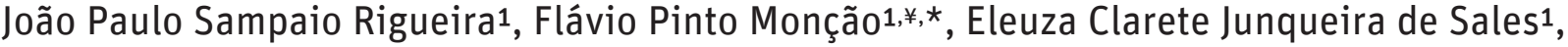 \\ Lara Maria Santos Brant², Daniel Ananias de Assis Pires¹, Aylle Medeiros Matos¹, \\ Gabriela Duarte Oliveira Leite로 Janaina Tayna Silva1, Jéssica Duarte Ramos Fonseca1, \\ Marielly Maria de Almeida Moura ${ }^{1}$ e Vicente Ribeiro Rocha Júnior ${ }^{1}$
}

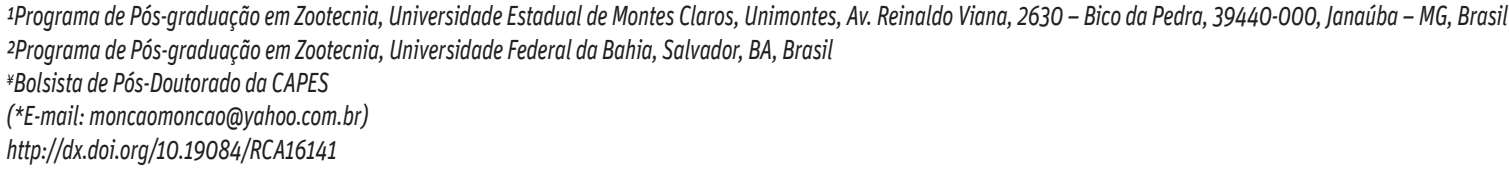

\section{R E S U M O}

Objetivou-se avaliar o efeito e o melhor nível de inclusão de glicerina bruta na ensilagem de capim Tifton 85 (Cynodon dactylon) sobre os parâmetros fermentativos e a composição química da silagem. Os tratamentos consistiram de silagem de capim Tifton 85 (controle) e silagem de capim Tifton 85 com quatro níveis de inclusão de glicerina bruta (1, 5, 10 e $15 \%$ de inclusão na matéria natural) durante a ensilagem. Utilizou-se um delineamento inteiramente casualizado sendo quatro tratamentos mais o controle com cinco repetições. Foi verificado que a inclusão de 1\%, 5\%, 10\% e 15\% de glicerina bruta diminuiu $18 \%, 18 \%, 20 \%$ e $22 \%$ o valor de pH em relação a silagem controle $(5,0)$, respectivamente. A inclusão de $15 \%$ de glicerina bruta na silagem de capim Tifton 85 aumentou 4,3\% o teor de carboidratos totais, $67,4 \%$ o teor de extrato etéreo e $17,7 \%$ o teor de nutrientes digestíveis totais em relação à silagem controle. A utilização de 15\% de glicerina bruta na matéria natural de capim Tifton 85 durante a ensilagem melhora o perfil fermentativo e as características nutricionais da silagem.

Palavras-chave: aditivo, composição química da silagem, gramínea, glicerol, potencial hidrogeniônico.

\begin{abstract}
A B S T R A C T
This study aimed to evaluate the effect and the best level of crude glycerin inclusion in grass ensiling Tifton 85 (Cynodon dactylon) on fermentative parameters and silage chemical composition. Treatments consisted of Tifton 85 grass silage (control) and silage Tifton 85 grass with four levels of inclusion of crude glycerin (1, 5, 10 and 15\% inclusion in natural matter) during ensiling. A completely randomized design with four treatments more control with five replications was used. It has been found that the inclusion of $1 \%, 5 \%, 10 \%, 15 \%$ crude glycerin decreased by $18 \%, 18 \%, 20 \%$ and $22 \%$, the $\mathrm{pH}$ value compared to the control silage (5.0), respectively. The inclusion of $15 \%$ crude glycerin in silage Tifton 85 grass increased by $4.3 \%$ in total carbohydrate, $67.4 \%$ in the ether extract and $17.7 \%$ in the total digestible nutrient content compared to control silage. The use of $15 \%$ crude glycerin in the natural field of Tifton 85 grass during ensiling enhances the fermentation profile and the nutritional characteristics of silage.
\end{abstract}

Keywords: additive, silage chemical composition, grass, glycerol, hydrogenionic potential 


\section{INTRODUÇÃO}

O grande entrave da produção animal em regiões áridas e semiáridas do Brasil é o baixo regime pluviométrico associado à distribuição irregular das chuvas. Mesmo assim, verifica-se que algumas forrageiras apresentam elevada produção de biomassa no período chuvoso, desde que bem manejadas.

Dentre as forrageiras tropicais com potencial de cultivo, as gramíneas do gênero Cynodon se destacam pela sua elevada produtividade de massa por área (Oliveira et al., 2014a,b; Monção et al., 2016). No entanto, os animais não consomem todo o excedente de forragem produzida, o que demanda estocagem do material na forma de silagem ou feno para utilização no período de escassez de pasto (período de secas). Para garantir massa de forragem em quantidade aos animais, é necessário colher a mesma em idades entre 60 e 80 dias conforme verificado por Oliveira et al. (2016). Entretanto, a qualidade da gramínea é afetada quando colhida em idades acima de 60 dias (Monção et al., 2014; Oliveira et al., 2014b, 2016).

Durante a ensilagem de gramíneas, como o capim Tifton 85 (Cynodon dactylon), quando não são utilizados aditivos, intensa fermentação pode ocorrer, podendo produzir etanol, efluentes e gases gerando perdas no valor nutricional da forragem. Isso acontece devido à atividade de leveduras que utilizam os açúcares solúveis para o seu crescimento (Dias et al., 2014).

A ensilagem de capim Tifton 85 com aditivos pode melhorar o perfil fermentativo e/ou a qualidade da massa ensilada, podendo assim não comprometer o desempenho animal mesmo no período da seca.

A glicerina bruta (GB), um subproduto da produção de biodiesel, é um aditivo com potencial de utilização na ensilagem de capim Tifton 85 devido à elevada densidade energética, podendo melhorar o valor nutricional da forragem ensilada, pois contém, em média, 75 a $80 \%$ de glicerol, 80 a $90 \%$ de matéria seca, o que pode reduzir perdas durante a fermentação, sendo o restante composto por água, ácidos graxos (7 a 13\%), minerais oriundos dos catalisadores (2 a 3\%; principalmente sódio) e álcool (<0,5\%) (Kerr et al., 2009). Cerca de
80 gramas de glicerol são produzidos para cada litro de biodiesel (Thompson e He, 2006). Há, no entanto, poucos estudos sobre a utilização, efeito e níveis de GB durante o processo de ensilagem em forrageiras. Mas, pela grande disponibilidade de GB decorrente da produção de biodiesel e pelo poder de compensar a perda energética do material ensilado, torna-se interessante estudá-la como um aditivo promissor no processo de ensilagem.

Com base no exposto, objetivou-se por meio deste experimento avaliar o efeito e o melhor nível de inclusão de GB na ensilagem de capim Tifton 85 sobre os parâmetros da fermentação e da composição química da silagem obtida.

\section{MATERIAL E MÉTODOS}

O experimento foi realizado na Universidade Estadual de Montes Claros (UNIMONTES), Campus de Janaúba MG, localizado a 1552'38" Sul e $43^{\circ} 20^{\prime} 05^{\prime \prime}$ Oeste. A precipitação anual média é de $700 \mathrm{~mm}$ com temperatura anual média de $28^{\circ} \mathrm{C}$, umidade relativa do ar cerca de $65 \%$ e, segundo a classificação climática de Koppen, o tipo de clima predominante na região é o Aw (Antunes, 1994).

Os tratamentos experimentais consistiram de silagem do capim Tifton 85 (Cynodon dactylon) (controle) e silagem de capim Tifton 85 com quatro níveis de inclusão de GB $(1,5,10$ e $15 \%$ de inclusão na matéria natural) durante a ensilagem. Utilizou-se um delineamento inteiramente casualizado sendo quatro tratamentos mais o controle com cinco repetições. A composição da GB utilizada no experimento pode ser observada no Quadro 1.

O capim Tifton 85 foi coletado em área pré-instaladas (um ano) no campo agrostológico da Fazenda Experimental da UNIMONTES. Foi realizado o corte manual da forrageira a $5 \mathrm{~cm}$ do solo e outro após 65 dias de rebrota para realização da ensilagem. $\mathrm{O}$ material foi triturado em máquina trituradora-picadora acoplada em motor elétrico. As facas da máquina foram reguladas para triturar a forragem e obter tamanho de partículas de $1,5 \mathrm{~cm}$. Após trituração e homogeneização de todo o material, cinco pilhas foram formadas e adicionado o aditivo GB nas respectivas proporções. 
Quadro 1 - Níveis de garantia de glicerina bruta e composição química da cana-de-açúcar (Saccharum officinarum) in natura, \% da matéria seca

\begin{tabular}{lc}
\hline Variáveis & Glicerina Bruta (\%) \\
\hline Glicerol Total & 86,9 \\
Matéria Seca & 89,5 \\
Metanol & $<0,01$ \\
$\mathrm{pH}$ & 5,3 \\
Umidade & 9,2 \\
Proteína Bruta & 0,4 \\
FDN & - \\
FDA & - \\
Extrato Etéreo & 10,0 \\
Cinzas & 3,2 \\
Sódio & 1,3 \\
Cloro & 1,9 \\
Potássio & $<0,1$ \\
\hline
\end{tabular}

FDN - Fibra em detergente neutro; FDA - Fibra em detergente ácido

Para ensilagem, foram utilizados silos experimentais de PVC, de pesos conhecidos, com $50 \mathrm{~cm}$ de comprimento e $10 \mathrm{~cm}$ de diâmetro. No fundo os silos continham $10 \mathrm{~cm}$ de areia seca, separada da forragem por uma espuma para quantificação do efluente produzido. Após a completa homogeneização da forragem com o aditivo, a mesma foi depositada nos silos e compactada com auxílio de um êmbolo de madeira. Para cada tratamento quantificou-se a densidade da silagem e tendo sido ensilados aproximadamente $3 \mathrm{~kg}$ do material triturado da forragem fresca conforme recomendação de Ruppel et al. (1995) com aplicação de uma densidade de compactação de aproximadamente 500 kg/ $\mathrm{m}^{3}$ por silo. Após o enchimento, os silos foram fechados com tampas de PVC dotadas de válvula tipo "bunsen", vedados com fita adesiva e pesados em seguida.

Os silos foram armazenados, mantidos à temperatura ambiente, com a abertura feita 60 dias após a ensilagem. Após a abertura, foram coletadas amostras no meio do silo após o descarte da parte superior das silagens que apresentasse presença de fungos. As amostras foram pré-secas em estuda de ventilação forçada com temperatura de $55^{\circ} \mathrm{C}$ até apresentarem peso constante. $\mathrm{O}$ material pré-seco foi moído em moinho tipo "willey" com peneiras de crivo $1 \mathrm{~mm}$ e armazenado em potes plásticos, devidamente identificados.

Para análises de $\mathrm{pH}$ foram coletadas subamostras de $25 \mathrm{~g}$ e adicionados $100 \mathrm{~mL}$ de água e, após repouso de 2 horas, realizou-se a leitura de $\mathrm{pH}$, utilizando-se um potenciômetro. Para determinação do $\mathrm{N}$-amoniacal $\left(\mathrm{N}-\mathrm{NH}_{3}\right)$, foi coletada uma subamostra de $25 \mathrm{~g}$, sendo adicionados $200 \mathrm{~mL}$ de uma solução de $\mathrm{H}_{2} \mathrm{SO}_{4}(0,2 \mathrm{~N})$, permanecendo em repouso por 48 horas e, em seguida, realizou-se a filtragem em papel de filtro Whatman 54, sendo que esse filtrado foi armazenado em geladeira para posterior determinação do $\mathrm{N}^{-\mathrm{NH}_{3}}$ (Bolsen et al., 1992).

As perdas de matéria seca nas silagens sob as formas de gases e efluentes foram quantificadas por diferença de peso, segundo Schmidt et al. (2011). Pela equação abaixo, foram obtidas as perdas por efluentes:

$\mathrm{E}=(\mathrm{Pab}-\mathrm{Pen}) /(\mathrm{MVfe}) \times 1000$, onde:

E: produção de efluentes $(\mathrm{kg} /$ tonelada de massa verde);

Pab: peso do conjunto (balde+tampa+areia úmida+pano) na abertura $(\mathrm{kg})$;

Pen: peso do conjunto (balde+tampa+areia seca+pano) na ensilagem $(\mathrm{kg})$;

MVfe: massa verde de forragem ensilada $(\mathrm{kg})$.

A perda de matéria seca na forma de gases foi calculada pela diferença entre o peso bruto da matéria seca ensilada inicial e final, em relação à quantidade de MS ensilada, descontados o peso do conjunto silo e areia seca, conforme a equação abaixo:

$$
\begin{gathered}
G=[(\text { PCen }- \text { Pen }) \times \text { MSen }]-[(\text { PCab-Pen }) \times \text { MSab }] \\
\text { x } 100[(\text { PCen }- \text { Pen }) \times \text { MSen }]
\end{gathered}
$$

Em que:

G: perdas por gases (\% MS);

PCen: peso do balde cheio na ensilagem $(\mathrm{kg})$; 
Pen: peso do conjunto (balde+tampa+areia seca+pano) na ensilagem $(\mathrm{kg})$;

MSen: teor de matéria seca da forragem na ensilagem;

PCab: peso do balde cheio na abertura (kg);

MSab: teor de matéria seca da forragem na abertura.

A silagem correspondente a cada um dos tratamentos, após pré-secagem, foi analisada quanto aos teores de matéria seca (MS), matéria mineral (cinzas), extrato etéreo (EE), proteína bruta (PB), conforme descrito pela (AOAC, 1990), e os teores de fibra em detergente neutro (FDN) e fibra em detergente ácido (FDA) pelo método sequencial, conforme procedimentos descritos por Van Soest et al. (1991). Os conteúdos de nitrogênio insolúvel em detergente neutro (NIDN) e nitrogênio insolúvel em detergente ácido (NIDA) foram determinados segundo Licitra et al. (1996). O teor de carboidratos totais (CT) foi estimado pela equação:

\section{$\mathrm{CT}(\%)=100[\%$ Umidade+PB(\%)+EE(\%)+cinzas(\%)]}

e os de carboidratos não fibrosos (CNF) segundo Sniffen et al. (1992).

Os nutrientes digestíveis totais (NDT) foram estimados por meio da fórmula

$\mathrm{NDT}=40,2625+0,1969 \mathrm{~PB}+0,4028 \mathrm{CNF}+1,903 \mathrm{EE} 0,137$ 9FDA (Weiss, 1998).

Os dados foram submetidos a analise de variância e, quando o teste de "F" foi significativo, para efeito de comparação da testemunha, em relação a cada nível de inclusão de GB utilizou-se o teste de Dunnett $(\mathrm{P}<0,05)$, por meio do procedimento GLM do SAS (SAS Institute, 2004) e os níveis de inclusão de glicerina foram submetidos ao estudo de regressão $(\mathrm{P}<0,05)$, excluindo-se a testemunha, por meio do programa SISVAR (Ferreira, 2011). A seleção do modelo de melhor ajuste teve por base a significância do teste de " $F$ " na análise de variância para regressão, a tendência dos dados e o coeficiente de determinação $\left(R^{2}\right)$.

\section{RESULTADOS E DISCUSSÃO}

A inclusão da GB na ensilagem de capim Tifton 85 reduziu o valor de $\mathrm{pH}$ da silagem. Foi verificado que a inclusão de $1 \%, 5 \%, 10 \%$ e $15 \%$ de GB diminuiu $18 \%, 18 \%, 20 \%$ e $22 \%$ o valor de $\mathrm{pH}$ em relação à silagem controle $(5,0)$, respectivamente (Quadro 2).

Os valores de $\mathrm{pH}$ são bastante influenciados pelos teores de matéria seca (MS) e carboidratos solúveis da planta durante a fermentação. Nesta pesquisa, os teores de MS foram alterados com o uso da GB (67,5\%), sendo a maior média observada no tratamento com $10 \%$ de GB em relação à silagem controle $(41,1 \%)$. Normalmente, a grande dificuldade de ensilar gramíneas forrageiras consiste no teor de MS que fica abaixo do recomendado (28 a $35 \%$ de MS) para obter elevada conservação dos nutrientes.

Neste estudo, os teores de MS ficaram acima do proposto, porém verificou-se que tal não foi impasse para obter uma fermentação satisfatória. Elevados teores de MS durante a ensilagem dificultam bastante o processo de compactação, o que pode elevar os níveis de oxigênio remanescente do material favorecendo o crescimento de bactérias e clostrídeos indesejáveis. Provavelmente, a inclusão de GB, devido às suas características químicas, associadas à compactação da massa ensilada favoreceu o desenvolvimento de bactérias homo e heterofermetativas, produzindo ácido acético e lático, justificando os menores valores de $\mathrm{pH}$ nas silagens tratadas. A elevação do teor de MS nas silagens tratadas se deve ao elevado teor de MS da GB (próximo de 90\%) (Quadro 1). Mas de forma geral, mesmo tendo ensilado o capim Tifton 85 em idade maior (65 dias), os resultados de $\mathrm{pH}$ permitem inferir que houve condições para fermentação de qualidade. Isso, possivelmente, foi também influenciado pela regulagem da máquina trituradora-picadoura, que possibilitou obter um tamanho de partícula ideal $(1,5 \mathrm{~cm})$ para compactação da massa no momento da ensilagem. Addah et al. (2011) ensilaram forrageiras temperadas com $48 \%$ de MS e também não verificaram problemas com a fermentação $(\mathrm{pH}=4,9)$. Hu et al. (2009) também não observaram efeitos negativos na fermentação de silagens de milho ensiladas com dois teores de MS (33,1\% vs. 40,6\%). Na prática, 
Quadro 2 - Perfil fermentativo e composição químico bromatológica de capim Tifton 85 sob níveis de glicerina bruta na matéria natural

\begin{tabular}{|c|c|c|c|c|c|c|c|}
\hline \multirow{2}{*}{ Variáveis } & \multirow[b]{2}{*}{ Controle } & \multicolumn{4}{|c|}{ Nível de Inclusão (\%) } & \multirow[t]{2}{*}{ EPM } & \multirow[t]{2}{*}{ P- Valor } \\
\hline & & 1 & 5 & 10 & 15 & & \\
\hline $\mathrm{pH}$ & 5,0 & ${ }^{*} 4,1$ & ${ }^{*} 4,1$ & ${ }^{*} 4,0$ & $* 3,9$ & 0,1 & 0,52 \\
\hline $\mathrm{NNH}_{3}, \% \mathrm{NT}$ & 0,13 & 0,15 & 0,14 & 0,14 & 0,12 & 0,01 & 0,56 \\
\hline MS & 41,1 & 47,7 & 60,5 & $* 67,5$ & 56,30 & 6,2 & 0,27 \\
\hline Cinzas, \% MS & 7,85 & 7,95 & 6,86 & 6,86 & ${ }^{*} 4,27$ & 0,24 & $<0,01$ \\
\hline $\mathrm{PB}, \% \mathrm{MS}$ & 9,11 & 6,41 & 6,30 & 6,63 & $* 5,83$ & 0,66 & 0,86 \\
\hline FDN, \% MS & 68,7 & 65,5 & $* 56,9$ & $* 54,5$ & $* 50,6$ & 2,2 & 0,02 \\
\hline FDA, \% MS & 43,0 & 43,2 & 35,0 & 36,5 & 34,9 & 2,9 & 0,26 \\
\hline HEM, \% MS & 25,8 & 22,3 & 21,9 & ${ }^{*} 18,0$ & $* 15,7$ & 1,3 & 0,07 \\
\hline NIDA, \% MS & 0,034 & 0,058 & 0,031 & 0,025 & 0,015 & 0,005 & $<0,01$ \\
\hline NIDN, \% MS & 0,287 & 0,037 & 0,039 & 0,030 & 0,031 & 0,004 & 0,50 \\
\hline $\mathrm{EE}, \% \mathrm{MS}$ & 1,52 & 3,49 & 3,38 & 3,67 & $* 4,67$ & 0,42 & 0,43 \\
\hline $\mathrm{CT}, \% \mathrm{MS}$ & 81,5 & 82,2 & 83,5 & 82,8 & $* 85,2$ & 0,8 & 0,13 \\
\hline $\mathrm{CNF}, \% \mathrm{MS}$ & 10,9 & 16,4 & ${ }^{*} 26,3$ & $* 28,1$ & $* 34,4$ & 2,3 & 0,01 \\
\hline NDT, \% MS & 43,40 & ${ }^{*} 48,8$ & $* 53,7$ & $* 54,8$ & $* 59,3$ & 1,6 & 0,02 \\
\hline
\end{tabular}

pH - Potencial hidrogênionico; $\mathrm{NNH}_{3}$ - Nitrogênio amoniacal; NT- Nitrogênio total; MS - Matéria seca; PB - Proteína bruta; FDN - Fibra em detergente neutro; FDA - Fibra em detergente ácido; NIDA - Nitrogênio insolúvel em detergente ácido; NIDN - Nitrogênio insolúvel em detergente neutro; EE - Extrato etéreo; CT Carboidratos totais; HEM - Hemicelulose; CNF - Carboidratos não fibrosos; NDT - Nutrientes digestíveis totais; EPM - Erro padrão da média

deve-se garantir homogeneidade do tamanho das partículas da biomassa a ensilar $(1,5 \mathrm{~cm})$ e adotar estratégias eficientes de compactação desta. A vedação do silo também é uma etapa de extrema importância na conservação e proteção da massa ensilada. Quando bem realizada, evita ou reduza a entrada de oxigênio para o interior do silo, o que conserva a massa e diminui a fermentação clostrídica.

A utilização de GB na ensilagem não afetou $(\mathrm{P}=0,56)$ os teores de nitrogênio amoniacal $\left(\mathrm{N}-\mathrm{NH}_{3}\right)$ da silagem, sendo reportada média de 0,13\% do nitrogênio total (NT). O N-NH gens é um indicador de perdas de nitrogênio do material e do perfil fermentativo juntamente com o pH. Mcdonald et al. (1981) inferiram que a falta de estabilidade na fermentação da silagem resulta na degradação extensiva de aminoácidos em amônia, $\mathrm{CO}_{2}$ e aminas incrementando os teores de $\mathrm{N}-\mathrm{NH}_{3}$, o que possivelmente não ocorreu nas silagens de capim Tifton 85 tratadas ou não com GB. Dias et al. (2014) também não verificaram alterações na concentração de $\mathrm{N}_{-} \mathrm{NH}_{3}$ quando utilizaram $1 \%, 2 \%$,
3\% e 4\% (base da MS) de GB na ensilagem de cana-de-açúcar (Saccharum officinarum). Os autores constataram, ainda, que a inclusão de GB reduziu em $18,1 \%$ as perdas no material ensilado. Em estudo com inclusão de até $9 \%$ de GB na matéria natural de silagem de cana ensilada por 45 e 90 dias, Santos et al. (2015) não verificaram mudanças na concentração de ácido acético $(1,1 \%$ da $\mathrm{MS})$, propiônico ( $0,3 \%$ da MS) e metanol (6,8\% da MS).

Os teores de cinzas e proteína bruta (PB) das silagens tratadas com $15 \%$ de GB foram respectivamente $45,6 \%$ e $36 \%$ inferiores aos da silagem controle (Quadro 1). A GB parece não apresentar em sua composição componentes para alterar os teores de cinzas e PB como verificado. Logo, as reduções verificadas provavelmente são efeitos de diluição desses ingredientes na matéria seca, o que possibilitou estimar menores valores (Santos et al., 2015). Entretanto, é recomendado que seja corrigido o teor de PB da silagem de capim Tifton 85 tratada por não atender os requerimentos mínimos de 70 a 100 gramas de PB para cada quilograma de matéria seca pela microbiota ruminal reproduzir 
e sintetizar proteína de origem microbiana (Van Soest, 1991; Detman et al., 2014).

A inclusão de $1 \%$ de GB na ensilagem reduziu $0,24 \%$ os teores de cinzas como pode ser observado na equação de regressão ( $\hat{Y}=8,31-0,24^{x} ; R^{2}=0,84$; Figura 1). A variação entre a menor e o maior nível de inclusão de GB foi de 46,3\%. É válido destacar o provável efeito da diluição desses nutrientes, pois Kerr et al. (2009) ressaltaram que a inclusão de GB pode elevar os níveis de sódio, o que consequentemente poderia incrementar levemente os teores de cinzas.

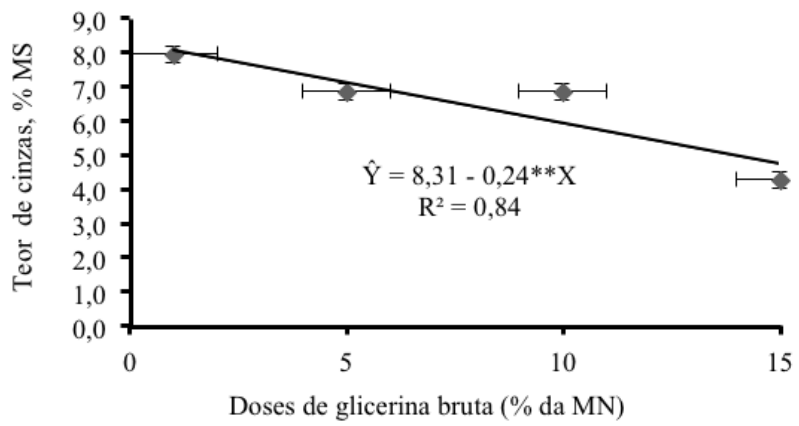

Figura 1 - Teor de cinzas (\% da matéria seca) da silagem de capim Tifton 85 com níveis de glicerina bruta [\% da matéria natural (MN)].

O efeito de diluição também foi verificado nos teores de fibra em detergente neutro (FDN) com reduções de $17,2 \%$, 20,7\% e $26,3 \%$ quando adicionaram 5\%, $10 \%$ e $15 \%$ de GB na matéria natural do

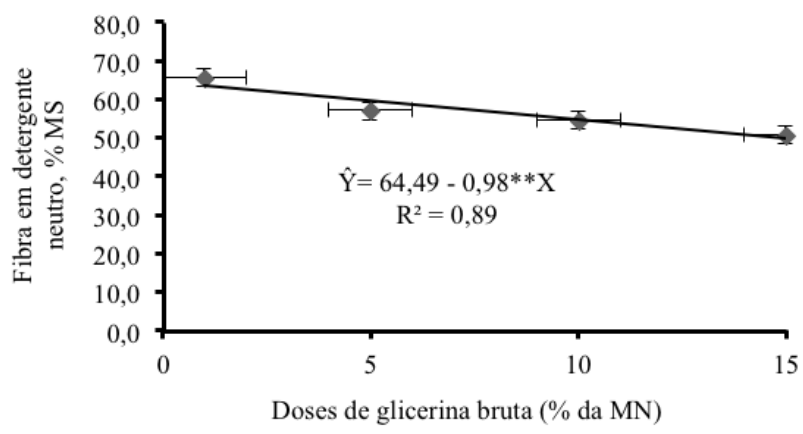

Figura 2 - Teor de fibra em detergente neutro (\% da matéria seca) da silagem de capim Tifton 85 com níveis de glicerina bruta [\% da matéria natural $(\mathrm{MN})]$. capim Tifton 85, respectivamente. Entre o menor e maior nível de inclusão de GB, as reduções de FDN foram de 26,3\% (Figura 2).

No entanto, é muito importante mais pesquisa nesse sentido com ênfase na degradabilidade ruminal da MS e FDN ou digestão total da FDN no trato gastrointestinal, visto que a GB apresenta moderada concentração de extrato etéreo $(10 \%$ da MS), o que pode afetar à ação dos microrganismos ruminais aos substratos reduzindo a utilização dos carboidratos da parede celular, afetando a síntese de proteína microbiana. Para os teores de EE, as diferenças foram verificadas apenas nas silagens tratadas com $15 \%$ de GB, sendo reportados incrementos de $67,4 \%$ no teor de EE em relação à silagem controle $(1,52 \%)$ (variação verificada entre a silagem controle e a silagem com $15 \%$ de inclusão de glicerina bruta) Esse aumento foi repercutido sobre as estimativas dos carboidratos não fibrosos $(\mathrm{CNF})$, sendo que para cada unidade percentual de GB aplicado na silagem de capim Tifton 85, houve acréscimo de $1,17 \%$ no teor de CNF conforme pode ser verificado na Figura 3.

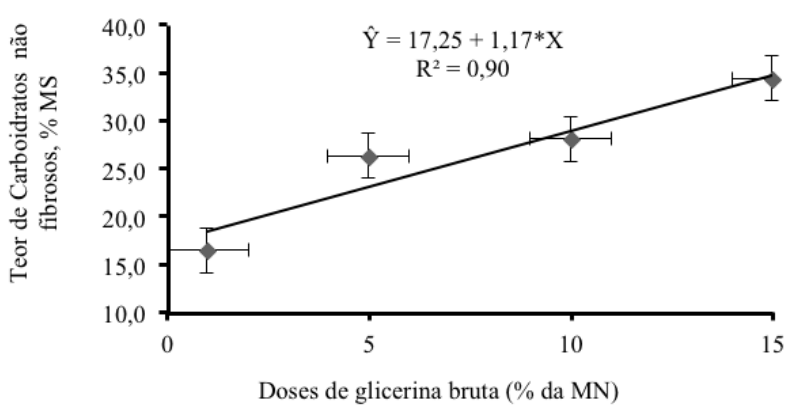

Figura 3 - Teor de carboidratos não fibrosos (\% da matéria seca) da silagem de capim Tifton 85 com níveis de glicerina bruta [\% da matéria natural (MN)].

A inclusão de $15 \%$ de GB na silagem de capim Tifton 85 aumentou $4,3 \%$ o teor de carboidratos totais (CT) em relação à silagem controle $(81,5 \%)$. Entre os níveis, não foi verificada diferença $(\mathrm{P}>0,05)$ para os teores de CT com média de $83,4 \%$. Os teores de nutrientes digestíveis totais (NDT) foram influenciados com a aplicação de GB. Houve aumentos de 
$11,1 \%, 19,2 \%, 20,8 \%$ e $26,8 \%$ quando se adicionou $1 \%, 5 \%, 10 \%$ e $15 \%$, respectivamente em relação à silagem controle $(43,4 \%)$. Na Figura 4 pode ser verificado que com o aumento de $1 \%$ de GB para $15 \%$ durante a ensilagem de capim Tifton 85 , houve incremento de $17,7 \%$ no teor de NDT, sendo reportado incremento de $0,7 \%$ nos níveis de energia para cada quilograma de GB aplicado.

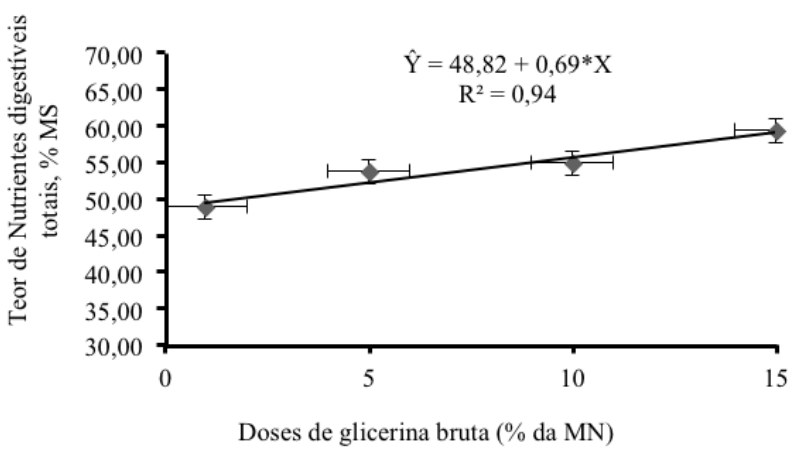

Figura 4 - Teor de nutrientes digestíveis totais (\% da matéria seca) da silagem de capim Tifton 85 com níveis de glicerina bruta [\% da matéria natural (MN)].

Os resultados gerados nessa pesquisa têm grande impacto na produção animal Brasileira e, sobretudo, em regiões de clima árido e semiárido entre os trópicos. Existem regiões marcadas por secas severas, baixos índices pluviométricos e distribuição irregular das chuvas e a própria sazonalidade de produção das plantas forrageiras que limitam a produção animal ao longo do ano, seja por déficit quantitativo ou qualitativo de forragem. Todavia, no período chuvoso ocorre acúmulo de forragem que é necessário armazenar para utilização no momento de escassez de alimentos para os animais. Dessa forma, o uso de GB, um coproduto da indústria de biodiesel, de baixo custo, na ensilagem de gramíneas tropicais, incrementa os teores de energia da dieta, o que reduz a utilização de insumos energéticos como o milho (Zea mays) e sorgo (Sorghum bicolor), que apresentam elevados valores de aquisição no mercado. Conforme verificado por Monção et al. (2016) o Tifton 85 apresenta teor de proteína bruta variando de 9 a $14 \%$ com idade de 79 a 28 dias de manejo de rebrota quando utilizados $50 \mathrm{~kg}$ de nitrogênio. Logo, estratégias de manejo do pasto podem reajustar os níveis de nutrientes para a ensilagem e atender às exigências dos animais. Mesmo assim, quando bem planejada, o uso de suplementação estratégica pode melhorar o perfil fermentativo da fração fibrosa da silagem no rúmen. Algumas pesquisas relatam que o uso de GB em dietas para bovinos (Wilbert et al., 2013) e ovinos (Lage et al., 2010) pode alterar o consumo de matéria seca. No entanto, outras pesquisas como a de Long et al. (2015) recomendaram a inclusão de $10 \%$ de GB na MS que não afeta a ingestão de nutrientes em bovinos de corte. Mesmo apresentando alto teor de EE, os mesmos autores não observaram efeito da GB sobre a degradação ruminal da fibra, mas relataram incremento de ácido propiônico no rúmen de novilhas. Em pesquisas com vacas produtoras de leite, Wilbert et al. (2013) demonstraram que o uso de até $12 \%$ de GB na MS de dietas contendo silagem de sorgo e feno de alfalfa (Medicago sativa) não altera o consumo de matéria seca, produção de leite, lactose e sólidos totais do leite. Mas, os mesmos verificaram um aumento no teor de proteína e glicose no leite. Desta forma, a utilização de GB na ensilagem de capim Tifton 85, além de melhorar o perfil fermentativo da silagem, com redução de perdas, é uma alternativa para melhorar a produção de carne e leite ou para reduzir os custos de produção, principalmente com a alimentação animal.

\section{CONCLUSÃO}

A utilização de $15 \%$ glicerina bruta na matéria natural de capim Tifton 85 durante a ensilagem melhora o perfil fermentativo e as características nutricionais da silagem.

\section{AGRADECIMENTOS}

À Fundação de Amparo à Pesquisa do Estado de Minas Gerais (FAPEMIG), ao Banco do Nordeste do Brasil (BNB), ao Conselho Nacional de Desenvolvimento Científico e Tecnológico. (CNPq) e a Coordenação de Aperfeiçoamento de Pessoal de Nível Superior (CAPES) pelo auxílio financeiro e pelas bolsas de estudo concedidas. 


\section{REFERÊNCIAS BIBLIOGRÁFICAS}

Addah, W.; Baah, J.; Groenewegen, P.; Okine, E.K.\& McAllister, T.A. (2011) - Comparison of the fermentation characteristics, aerobic stability and nutritive value of barley and corn silages ensiled with or without a mixed bacterial inoculant. Canadian Journal of Animal Science, vol. 91, n. 1, p. 133-146. http://dx.doi.org/10.4141/ CIAS10071

Antunes, F.Z. (1994) - Caracterização climática. Informe Agropecuário, vol. 17, n. 181, p. 15-19.

AOAC (1990) - Agricultural Chemists. Official methods of analysis. 16.ed. Association of Official Analytical Chemists, Washington, D.C. 1094 p.

Bolsen, K.K.; Lin, C.; Brent, B.E. \& Gadeken, D. (1992) - Effect of silage additives on the microbial succession and fermentation process of alfalfa and corn silages. Journal of Dairy Science, vol. 75, n. 11, p. 3066-3083. http://dx.doi.org/10.3168/jds.S0022-0302(92)78070-9

Detmann, E.; Valente, E.E.L.; Batista, E.D. \& Huhtanen, P. (2014) - An evaluation of the performance and efficiency of nitrogen utilization in cattle fed tropical grass pastures with supplementation. Livestock Science, vol. 162, p. 141-153. https://doi.org/10.1016/j.livsci.2014.01.029

Dias, A.M.; Ítavo, L.C.V.; Ítavo, C.C.B.F.; Blan, L.R.; Gomes, E.N.O.; Soares, C.M.; Leal, E.S.; Nogueira, E. \& Coelho, E.M. (2014) - Ureia e glicerina bruta como aditivos na ensilagem de cana-de-açúcar. Arquivo Brasileiro de Medicina Veterinária e Zootecnia, vol. 66, n. 6, p. 1874-1882. http://dx.doi.org/10.1590/1678-7349

Ferreira, D.F. (2011) - Sisvar: A computer statistical analysis system. Ciência e Agrotecnologia, vol. 35, n. 6, p. 1039-1042. http://dx.doi.org/10.1590/S1413-70542011000600001

Hu, W.; Schmidt, R.J.; Mcdonell, E.E.; Klingerman, C.M. \& Kung Jr., L. (2009) - The effect of Lactobacillus buchneri 40788 or Lactobacillus plantarum MTD-1 on the fermentation and aerobic stability of corn silages ensiled at two dry matter contents. Journal of Dairy Science, vol. 92, n. 8, p. 3907-3914. https://doi.org/10.3168/ jds.2008-1788

Kerr, B.J.; Weber, T.E.; Dozier, W.A. \& Kidd, M.T. (2009) - Digestible and metabolizable energy content of crude glycerin originating from different sources in nursery pigs. Journal of Animal Science, vol. 87, n. 12, p. 4042-4049. http://dx.doi.org/10.2527/jas.2008-1676

Lage, J.F.; Paulino, P.V.; Pereira, L.G.R.; Valadares, F S.C.; De Oliveira, A.S.; Detmann, E.; Souza, N.K.P. \& Lima, J.C.M. (2010) - Glicerina bruta na dieta de cordeiros terminados em confinamento. Pesquisa Agropecuária Brasileira, vol. 45, n. 9, p. 1012-1020. http://dx.doi.org/10.1590/S0100-204X2010000900011

Licitra, G.; Hernandez, T.M. \& Van Soest, P.J. (1996) - Standardization of procedures for nitrogen fractionation of ruminant feeds. Animal Feed Science and Technology, vol. 57, n. 4, p. 347-358. https://doi. org/10.1016/0377-8401(95)00837-3

Long, C.J.; Sneed, A.D.; Schroeder, A.R. \& Felix, T.L. (2015) - Effects of dietary glycerin on growth performance, carcass characteristics, and rumen metabolism of beef cattle. The Professional Animal Scientist, vol. 31, n. 6, p. 568-576. http://dx.doi.org/10.15232/pas.2015-01426

McDonald, P.; Henderson, A.R. \& Heron, S.J.E. (1991) - The biochemistry of silage. 2. ed. Chalcomb Publisher, Marlow. 340 p.

Monção, F.P.; Oliveira, E.R.; Gabriel, A.M.A.; Nascimento, F.A.; Pedroso, F.W. \& Freitas, L.L. (2016) Nutritional parameters of leaf blade from different tropical forages. Scientia Agraria Paranaensis, vol. 15, n. 2, p. 185-193. http://dx.doi.org/10.18188/1983-1471/sap.v15n2p185-193

Monção, F.P.; Oliveira, E.R.; Gabriel, A.M.A.; Souza, R.; Moura, L.V.; Lempp, B.L. \& Santos, M.V. (2014a) Degradabilidade ruminal de diferentes gramíneas do gênero Cynodon spp. em quatro idades de corte. Revista Brasileira de Ciências Agrárias, vol. 9, n. 2, p. 301-307. http://dx.doi.org/10.5039/agraria.v9i2a4012

Oliveira, E.R.; Monção, F.P.; Gabriel, A.M.A.; Moura, L.V.; Lempp, B.; Santos, M.V. \& Souza, R. (2014b) - Degradação ruminal da biomassa de fenos de gramíneas do género Cynodon spp. Revista de Ciências Agrárias, vol. 37, n. 2, p. 214-220.

Oliveira, E.R.; Monção, F.P.; Gabriel, A.M.A.; Silva, L.H.X.; Carbonari, V.M.S.; Pedroso, F.W.; Pereira, T.L. \& Nascimento, F.A. (2016) - Valor nutricional do colmo de gramíneas tropicais. Scientia Agraria Paranaensis, vol. 15, n. 3, p. 256-264. http://dx.doi.org/10.18188/1983-1471/sap.v15n3p256-264 
Oliveira, E.R.; Monção, F.P.; Gordin, C.L.; Gabriel, A.M.A.; Lempp, B.; Santos, M.V.; Reis, S.T. \& Moura, L.V. (2014a) - Degradabilidade ruminal da matéria seca de folhas e colmo de genótipos de Cynodon spp. em quatro idades de rebrota. Semina: Ciências Agrárias, vol. 35, n. 5, p. 2659-2672.

Ruppel, K.A.; Pitt, R.E.; Chase, L.E. \& Galton, D.M. (1995) - Bunker silo management and its relationship to forage preservation on dairy farms. Journal of Dairy Science, vol. 78, n. 1, p. 141-153. http://dx.doi.org/10.3168/ jds.S0022-0302(95)76624-3

Santos, W.P.; Carvalho, B.F.; Ávila, C.L.S.; Dias Júnior, G.S.; Pereira, M.N. \& Schwan, R.F. (2015) - Glycerin as an additive for sugarcane silage. Annals of Microbiology, vol. 65, n. 3, p. 1547-1556. http://dx.doi.org/10.1007/ s13213-014-0993-x

Schmidt, P; Junior, P.R; Junges, D; Dias, T.L.; Almeida, R. \& Mari, L.J. (2011) - Novos aditivos microbianos na ensilagem da cana-de-açúcar: composição bromatológica, perdas fermentativas, componentes voláteis e estabilidade aeróbia. Revista Brasileira de Zootecnia, vol. 40, n. 3, p. 543-549. http://dx.doi.org/10.1590/ $\underline{\text { S1516-35982011000300011 }}$

Sniffen, C.J.; O'Connor, J.D.; Van Soest, P.J.; Fox, D.G. \& Russell, J.B. (1992) - A net carbohydrate and protein system for evaluating cattle diets: II. Carbohydrate and protein availability. Journal of Animal Science, vol. 70, n. 12, p. 3562-3577. http://dx.doi.org/10.2527/1992.70113562x

Thompson, J.C. \& He, B.B. (2006) - Characterization of crude glycerol from biodiesel production from multiple feed stock. Applied Engineering in Agriculture, vol. 22, n. 1, p. 261-265. http://dx.doi.org/10.13031/2013.20272

Van Soest, P.J.; Robertson, J.B. \& Lewis, B.A. (1991) - Methods for dietary fiber neutral detergent and nonstarch polysaccharides in relation to animal nutrition. Journal of Dairy Science, vol. 74, n. 10, p. 3583-3597. http://dx.doi.org/10.3168/jds.S0022-0302(91)78551-2

Weiss, W.P. (1998) - Estimating the available energy content of feeds for dairy cattle. Journal of Dairy Science, vol. 81, n. 3, p. 830-839. https://doi.org/10.3168/jds.S0022-0302(98)75641-3

Wilbert, C.A.; Prates, E.R.; Barcellos, J.O.J. \& Schafhäuser, J. (2013) - Crude glycerin as an alternative energy feedstuff for dairy cows. Animal Feed Science and Technology, vol. 183, n. 3-4, p. 116-123. https://doi. org/10.1016/j.anifeedsci.2013.05.003 